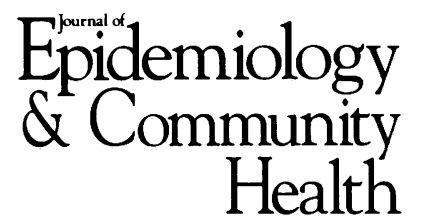

Editorials

\title{
Europe and health services research: systematic reviews and feedback from readers
}

I am very pleased that colleagues from continental Europe have accepted my invitation to join the reconstituted Editorial Board of this Journal. We now have members from Spain, Italy, The Netherlands, and Scandinavia, and expect others to join us soon. From June 1993 each number of the Journal will contain a guest editorial from one of these European colleagues telling us about health services research and other applied epidemiological work in their country or region.

I should point out that neither the inclusion of European colleagues nor the emphasis on health services research is in the least new. In the first number of this Journal (then called the British Fournal of Social Medicine) in 1947 the editors wrote that they were 'anxious to keep in close touch with centres of social medicine in other parts of the world'. The General Advisory Board which they had already formed included in that first number colleagues from Belgium, Denmark, France, Hungary, Italy, The Netherlands, Poland, Sweden, the United States, and Yugoslavia. The first volume in 1947 also included 'an attempt to estimate the value and limitations of routine school medical inspections ${ }^{1}$ together with an article on the nutritive value of diets provided to nursing mothers while in hospital ${ }^{2}$ which had a concluding section on 'the chief deficiencies and the means for their improvement'. The second volume-in 1948, the year in which the British National Health Service was begun-included articles on bed-states in Australia, New Zealand, and Canada ${ }^{3}$ (discussing length of stay and waiting lists, including both numbers of patients and waiting times), hospitals in Sweden, ${ }^{4}$ and the medical system in the United States. ${ }^{5}$
One fundamental aspect of health services research is the evaluation of earlier relevant research, published or unpublished. Colleagues from the Cochrane Centre in Oxford will also be contributing to several numbers of this Journal in 1993 , looking in particular at ways of standardising procedures for tracing and assessing previous work and for presenting the results of these reviews. We will continue our policy of commissioning reviews as well as accepting review articles that are offered to us, but we will endeavour to present structured abstracts for all these articles in which (for example) authors will explain the methods by which papers and their conclusions were included in or excluded from the overview. While acknowledging (to our publishers and printers) the long deadlines and other publishing constraints of a bi-monthly journal, I propose to reserve space for rapid responses and comments (in letter form) from readers on these review articles (and other papers) in order to promote increasing quality in our attempts at evaluation.

STUART DONNAN

Editor

1 Gordon I. School medical inspections, their value and limitations. British Fournal of Social Medicine 1947; 1: 238-50.

2 Cruickshank EWH, Stewart CP. Dietaries in maternity hospitals. British fournal of Social Medicine 1947; 1: 182-96.

3 Padley R. Bed-states in the Dominions. British foumal of Social Medicine 1948; 2: 45-52.

4 Dahlberg G. The Swedish bed-state. British Fournal of Social Medicine 1948; 2: $53-4$.

5 McKeown T. American medical services. British fournal of Social Medicine 1948; 2: 77-105.

\section{Ageing and later life}

The numbers of older people are increasing throughout the world. Although high birth rates make the elderly as a percentage of their populations seem relatively small in China, India, and much of Africa, where only $2 \%$ to $6 \%$ are aged 65 years or more, a majority of people in this broad age 'group' live in the developing world. Their numbers are set to grow significantly in the next 20 years. ${ }^{1}$ Even in the OECD countries and in those other countries where total population levels are now more stable, the proportion of the population that is aged $65+$ is still growing. In Britain, this total group now stands at about nine million and will be fairly steady for the next 20 years before the country witnesses a further growth as the post war 'baby boomers' reach retirement age. As in other developed industrial countries however, the major growth in the foreseeable future is in the population of very old people. Those aged over 85 account for most of the growth among 'the elderly' over the next 20 years, rising from 865000 to at least $1 \cdot 15$ million by $2001 .^{2}$

It has proved notoriously difficult to predict future population patterns reliably. For example, US demographers in the 1940s so seriously underestimated improvements in mortality rates that occurred in the following decades that 1990 actual figures for people aged $85+$ proved to be more than twice the expected number. ${ }^{3}$ This is important as numbers of old people obviously reflect a combination of birth rates 60 to 100 years earlier and survival rates during life. We have fairly reliable data on the former but the latter has proved elusive to predict, while actual numbers in a given geographical area are also affected by migration patterns throughout life. The projected figures cited above may be underestimates if mortality rates among the old fall faster than expected. Meanwhile the implications of these demographic data on 